Check for updates

Cite this: RSC Adv., 2017, 7, 28564

Received 24th February 2017

Accepted 24th May 2017

DOI: $10.1039 / \mathrm{c} 7 \mathrm{ra02330h}$

rsc.li/rsc-advances

\section{The influence of the constituent elements on the corrosion mechanisms of silver alloys in sulphide environments: the case of sterling silver}

\author{
I. Tissot, (DD *a O. C. Monteiro, (D) ${ }^{b}$ M. A. Barreiros, (D) ${ }^{c}$ J. Correia (D) ${ }^{b}$ \\ and M. F. Guerra iD d
}

\begin{abstract}
The corrosion of copper and silver in sulphide environments was assessed by several analytical techniques to investigate the influence of each one on the corrosion of sterling silver. The surface colour changes with the immersion time due to the formation of corrosion products composed of particles with distinct sizes and shapes and the consequent layer thickening. $\mathrm{Ag}_{2} \mathrm{~S}$ is the main corrosion product of silver. At early stages of corrosion, $\mathrm{Cu}$ develops $\mathrm{Cu}_{2} \mathrm{O}$ and $\mathrm{Cu}_{2} \mathrm{~S}$, and later $\mathrm{Cu}_{2} \mathrm{O}$ again. After the corrosion of sterling silver, pure $\mathrm{Cu}$ and $\mathrm{Ag}$ are compared, and the predominant influence of $\mathrm{Cu}$ at the first stages may be suggested whilst Ag mainly contributes to longer corrosion stages. The layer-by-layer corrosion structure observed for the sulphidation of sterling silver was not observed for its constituent elements.
\end{abstract}

\section{Introduction}

When exposed to high sulphide containing atmospheres, cultural heritage silver objects corrode. ${ }^{\mathbf{1 - 9}}$ To establish adequate conservation treatments, it is fundamental to identify the corrosion products formed at the surface and to fully describe the corrosion mechanisms. Although there is significant research in this area, the influence of the constituent elements of the silver alloy on the corrosion mechanism is far away from being clearly identified..$^{\mathbf{1 0 - 1 4}}$ In previous work, the corrosion of sterling silver (92.5 $\mathrm{wt} \%$ of $\mathrm{Ag}$ and $7.5 \mathrm{wt} \%$ of $\mathrm{Cu}$ ), one of the main silver alloys used in jewellery making,,15,16 in sulphide environments was investigated. ${ }^{10}$ In this study, it was suggested that the surface colour variation (from yellow to violet, blue grey and dark grey) is related to both the formation of distinct corrosion products and the corrosion layer thickness. At the early stages of corrosion, the corrosion products are mainly composed of $\mathrm{Cu}$ compounds and at longer corrosion times by either $\mathrm{Ag}_{2} \mathrm{~S}$ or $\mathrm{AgCuS}$. The corroded surface morphology suggests the development of a layer-by-layer film. The corroded layer structure is the result of overlapped layers with distinct compositions, continuously growing at different rates. The

${ }^{a}$ LIBPhys - UNL 2829-516 Caparica, Portugal \& Faculdade de Ciências, Universidade de Lisboa, Campo Grande, 1749-016, Lisboa, Portugal. E-mail: isabel.tissot@ archeofactu.pt

${ }^{b}$ Centro de Química e Bioquímica, Faculdade de Ciências, Universidade de Lisboa, Campo Grande, 1749-016 Lisboa, Portugal. E-mail: ocmonteiro@fc.ul.pt; jmcorreia@fc.ul.pt

${ }^{c}$ Laboratório Nacional de Energia e Geologia, LEN/UER, Estrada do Paço do Lumiar, 22, 1649-038 Lisboa, Portugal.E-mail: alexandra.barreiros@lneg.pt

${ }^{d}$ ArchAm - UMR 8096 CNRS, MAE, 21 allée de l'Université, 92023 Nanterre, France. E-mail: maria.guerra@cnrs.fr corrosion of $\mathrm{Ag}$ and $\mathrm{Cu}$ in high sulphide environments has been widely investigated, ${ }^{\mathbf{1 1 , 1 3 , 1 7 - 3 2}}$ however, the influence of the constituent elements on the corrosion mechanism of sterling silver was, from our knowledge, not studied yet.

It was demonstrated that $\alpha-\mathrm{Ag}_{2} \mathrm{~S}$ (acanthite) is the main corrosion product of pure Ag. The formation can occur either by direct conversion of $\mathrm{Ag}$ to $\mathrm{Ag}_{2} \mathrm{~S}$, by an oxidative dissolution of $\mathrm{Ag}$ to $\mathrm{Ag}^{+}$followed by the formation of $\mathrm{Ag}_{2} \mathrm{~S}$, or by the formation of $\mathrm{Ag}$ nanoparticles that are converted into $\mathrm{Ag}_{2} \mathrm{~S}^{6-11}$ These different corrosion mechanisms are dependent on the environment characteristics. The colour of the corroded surfaces depends on the size and shape of the $\mathrm{Ag}_{2} \mathrm{~S}$ particles. ${ }^{33}$ The oxidation of $\mathrm{Ag}$ and $\mathrm{Ag}_{2} \mathrm{~S}$ may lead to the formation of silver oxides ( $\mathrm{AgO}$ and $\mathrm{Ag}_{2} \mathrm{O}$ ), but it has also been reported the formation of $\mathrm{Ag}_{2} \mathrm{~S}$ over a $\mathrm{Ag}_{2} \mathrm{O}$ film layer. ${ }^{34}$

Copper sulphides are the resulting compounds of pure $\mathrm{Cu}$ corrosion in sulphide environments. There are several stoichiometric phases of copper sulphides, from copper-rich $\mathrm{Cu}_{2} \mathrm{~S}$ (chalcocite) to copper-poor CuS (covellite) phases. ${ }^{35,36}$ The corrosion mechanism involves the nucleation and growth of $\mathrm{Cu}_{x} \mathrm{~S}$ particles at the surface. Thicker films are composed of copper-rich phases whereas thinner films are constituted by copper-poor phases. ${ }^{35}$ Depending on the relative humidity level, a first layer of $\mathrm{Cu}_{2} \mathrm{O}$ is formed on the $\mathrm{Cu}$ surface. The $\mathrm{Cu}_{x} \mathrm{~S}$ growths over this oxide layer, firstly following a linear rate and then, when a minimum thickness is reached, following a parabolic rate. ${ }^{37-40}$ The colour of the corroded copper surfaces depends on the $\mathrm{Cu}_{2} \mathrm{~S}$ layer thickness. ${ }^{27}$ However, apart from studies on natural patinas, the colour variation of the copper corroded surface is rarely concerned in sulphidation mechanism investigations. ${ }^{41,42}$ 
The overlapped layers with distinct compositions of the silver-copper alloys corroded layer structure ${ }^{\mathbf{1 0}}$ should depend on the pure elements $(\mathrm{Ag}$ and $\mathrm{Cu}$ ) corrosion mechanisms. The present work is a continuation of the study on corrosion of silver alloy in sulphide environments ${ }^{\mathbf{1 0}}$ and aims to compare the corrosion mechanisms of sterling silver with those of its constituent metals. The colour of the corroded layers depending on the composition and thickness of the corrosion layers, and the contribution of each pure element to the colour variation of the corroded silver alloy were also investigated.

Samples of pure $\mathrm{Ag}$ and $\mathrm{Cu}$ employed by jewellers to fabricate sterling silver were corroded in a sulphide environment and the surfaces characterised using the analytical strategy applied for the previous study of sterling silver corrosion by Tissot et al. ${ }^{\mathbf{1 0}}$ The surfaces were optically characterised by ultraviolet-visible (UV-Vis) spectrophotometry, the surface morphology investigated by scanning electron microscopy with a field emission gun (SEM-FEG) and the surface elemental composition achieved by energy dispersive X-ray spectrometry (EDS) and by X-ray diffraction (XRD). The corrosion thickness was determined by ellipsometry.

\section{Material and methods}

\subsection{Silver and copper samples and accelerated ageing test conditions}

Sheets of $\mathrm{Cu}$ and $\mathrm{Ag}$ were acquired from a local jewellery supplier (Lima \& Teixeira, Lisbon), to test the pure metals employed by jewellers to fabricate sterling silver. A set of 11 samples of $1.5 \mathrm{~cm}^{2}$ area and $1 \mathrm{~mm}$ thickness were cut from the sheets and then abraded with SiC-paper with grits up to 1000 mesh, using the method described in Tissot et al. ${ }^{10}$ To remove grinding residues, the samples were washed with deionised water in an ultrasonic bath.

$\mathrm{The} \mathrm{Ag}$ and $\mathrm{Cu}$ samples were corroded by immersion in a $0.1 \mathrm{M} \mathrm{Na}_{2} \mathrm{~S}$ aqueous solution during the same immersion time as the sterling silver samples published in Tissot et al. ${ }^{\mathbf{1 0}}: 1,3,5$, 7, 15, 30, 60, 120, 240, 480 and 1020 minutes.

\subsection{Surface characterisation}

The analytical protocol described in Tissot et al. ${ }^{10}$ was applied to characterise the $\mathrm{Ag}$ and $\mathrm{Cu}$ samples surface. The methods and the analytical techniques are briefly summarised below.

The optical characterisation was carried out by UV-Vis spectrophotometry using a Shimadzu UV-2450PC spectrometer. The diffuse reflectance spectra (DRS) were recorded with a detecting wavelength ranging from 220 to $1400 \mathrm{~nm}$, using bare $\mathrm{Ag}$ and bare $\mathrm{Cu}$, prepared with the same surface finishing of the samples, as reference to the baselines. Absorption data $(\alpha / \Lambda)$ were calculated from reflectance data with Kubelka-Munk equations: $\alpha / \Lambda=(1-R)^{2} /(2 R)$, where $R$ is the reflectance and $\alpha$ and $\Lambda$ are the absorption and scattering coefficients, respectively.

Surface morphology was observed under a SEM-EDS Philips XL 30 FEG model operated with acceleration voltage from 10 to $25 \mathrm{kV}$. Semi-quantitative elemental composition was obtained with an EDS (EDAX) system equipped with a $\mathrm{Si}(\mathrm{Li})$ detector with a $3 \mu \mathrm{m}$ super ultra-thin window (SUTW), allowing detection of light elements. The X-ray spectra were collected in spot mode analysis for $300 \mathrm{~s}$ acquisition time.

Crystalline corrosion products were identified by XRD using a Philips X-ray diffractometer (PW 1730) with automatic data acquisition (APD Philips v3.6B) with a $\mathrm{Cu} \mathrm{K} \alpha$ radiation working at $40 \mathrm{kV} / 30 \mathrm{~mA}$. Data were collected with a 0.020 step size and an acquisition time of $200 \mathrm{~s} \mathrm{deg}^{-1}$. A selection of different ranges of $2 \theta$ was made to avoid the $\mathrm{Ag}$ and $\mathrm{Cu}$ diffraction peaks. Powder $\mathrm{X}$-ray diffraction files were obtained from the Pearson's Crystal Database (PCD).

The corrosion layer thickness was estimated by ex situ ellipsometric measurements using a Sentech SE400 Ellipsometer operating in PSA mode at a constant wavelength of $632.8 \mathrm{~nm}$. The ellipsometric parameters azimuthal angle $(\Psi)$ and phase shift $(\Delta)$, retrieved from the change of polarization state of the light beam upon reflection on the sample, were measured at two distinct angles of incidence $\left(\varphi=65^{\circ}\right.$ and $70^{\circ}$ for $\mathrm{Ag}$ and $\varphi=60^{\circ}$ and $70^{\circ}$ for $\mathrm{Cu}$ ). Due to the significant light absorption and increasing thickness of the corrosion layer with time, it was only possible to acquire the ellipsometric data for the $\mathrm{Ag}$ samples immersed until $30 \mathrm{~min}$ and for the $\mathrm{Cu}$ samples immersed until $60 \mathrm{~min}$. For longer immersion times, the reflected radiation intensity was too low to be analysed, like in the case of sterling silver. ${ }^{\mathbf{1 0}}$

\section{Results and discussion}

\subsection{Corroded silver surfaces characterisation}

Artificially aged Ag surfaces present colour variations that depend on the immersion time. Fig. 1 shows this colour variation that goes from light brown ( 1 and $3 \mathrm{~min}$ ) to blue ( 5 and 7 $\mathrm{min})$, blue-grey $(15,30,60$ and $120 \mathrm{~min}$ ) and grey (240 $\mathrm{min}$ onwards). Contrary to what has been suggested, ${ }^{33}$ the colours of the corroded Ag surfaces are different from those reported for corroded sterling silver. The latter, under the same conditions, are characterised by a colour variation with different tones of yellow, red, violet, blue and grey. ${ }^{\mathbf{1 0}}$

Fig. 2A presents the UV-Vis absorption spectra for the samples immersed during 1, 3, 5 and $7 \mathrm{~min}$. All these samples show an absorption band increase around $370 \mathrm{~nm}$, that can be ascribe to the presence of $\mathrm{Ag}$ nanoparticles. ${ }^{43}$ The sample immersed during 1 min has a broad band with a maximum absorption at $484 \mathrm{~nm}$, which can be attributed to the nucleation of amorphous $\mathrm{Ag}_{2} \mathrm{~S}$ with a particle size inferior to $10 \mathrm{~nm} .{ }^{44}$ The sample immersed during $3 \mathrm{~min}$ has a well-defined absorption band with a maximum at $528 \mathrm{~nm}$, corresponding to an estimated band gap energy of $1.2 \mathrm{eV}$, value reported for both $\mathrm{Ag}_{2} \mathrm{O}$ and $\mathrm{Ag}_{2} \mathrm{~S}$ band gap energies. ${ }^{45,46}$

As shown in Fig. 2B, the UV-Vis absorption spectra of the samples with immersion time longer than 15 min have a broad band between 370 and $480 \mathrm{~nm}$, similar to the one observed for the sample immersed during $1 \mathrm{~min}$. The UV-Vis spectra of samples immersed during 5, 7 and 15 minutes show another band which broadens with the immersion time increase and shifts towards higher wavelengths with a maximum absorbance 

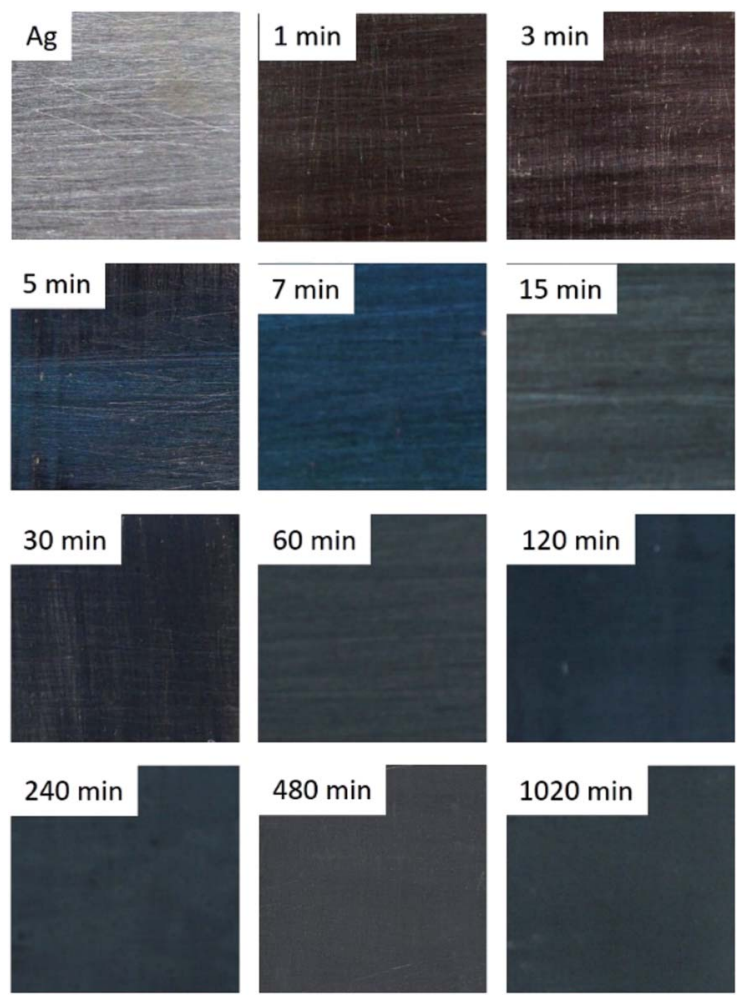

Fig. 1 Surface colour of the corroded Ag samples immersed during 1, $3,5,7,15,30,60,120,240,480$ and $1020 \mathrm{~min}$ in a $0.1 \mathrm{M} \mathrm{Na}_{2} \mathrm{~S}$ aqueous solution.

at $646 \mathrm{~nm}$ (5 min), $689 \mathrm{~nm}(7 \mathrm{~min})$ and $820 \mathrm{~nm}(15 \mathrm{~min})$, respectively. This band can be ascribed to the formation of $\mathrm{Ag}_{2} \mathrm{~S}$ particles, which size increases with the immersion time. ${ }^{44}$ The band energy gap estimated for the 7 min sample is $1.1 \mathrm{eV}$ that could correspond to the presence of $\mathrm{Ag}_{2} \mathrm{~S}$ particles. ${ }^{47}$

The UV-Vis spectra of the samples immersed during 60 and 120 minutes show a slight bump at $566 \mathrm{~nm}$ followed by a wide band with a maximum absorbance at $679 \mathrm{~nm}(60 \mathrm{~min})$ and at $839 \mathrm{~nm}$ (120 $\mathrm{min})$. At higher wavelengths, it is observed a slight increase with a maximum absorbance at $1141 \mathrm{~nm}$ (60 $\mathrm{min})$ and at $1123 \mathrm{~nm}$ (120 min). Fig. 2C shows the data obtained for the samples with immersion times of 240, 480 and 1020 minutes. The absorption spectrum of the 240 min sample has a small bump at $569 \mathrm{~nm}$ followed by a wide band with an absorbance decrease at around $1000 \mathrm{~nm}$. The sample immersed during $480 \mathrm{~min}$ has a wide band with a maximum of absorbance at $708 \mathrm{~nm}$. The $1020 \mathrm{~min}$ sample has a broad band with a slight bump at $575 \mathrm{~nm}$ followed by an absorbance decrease and then by another accentuated decrease at $1150 \mathrm{~nm}$. The bands broadening can be related to the corrosion layer increase.

The UV-Vis absorption data suggest the coexistence of $\mathrm{Ag}_{2} \mathrm{~S}$ and/or $\mathrm{Ag}_{2} \mathrm{O}$ particles with distinct sizes. For the samples immersed during short periods of time ( 1 to 3 minutes) there is a possible nucleation of small particles that increase in size with the immersion time, followed by the nucleation of new particles in a continuous corrosion process.

The surface morphology and the elemental composition of the compounds formed during corrosion were investigated by
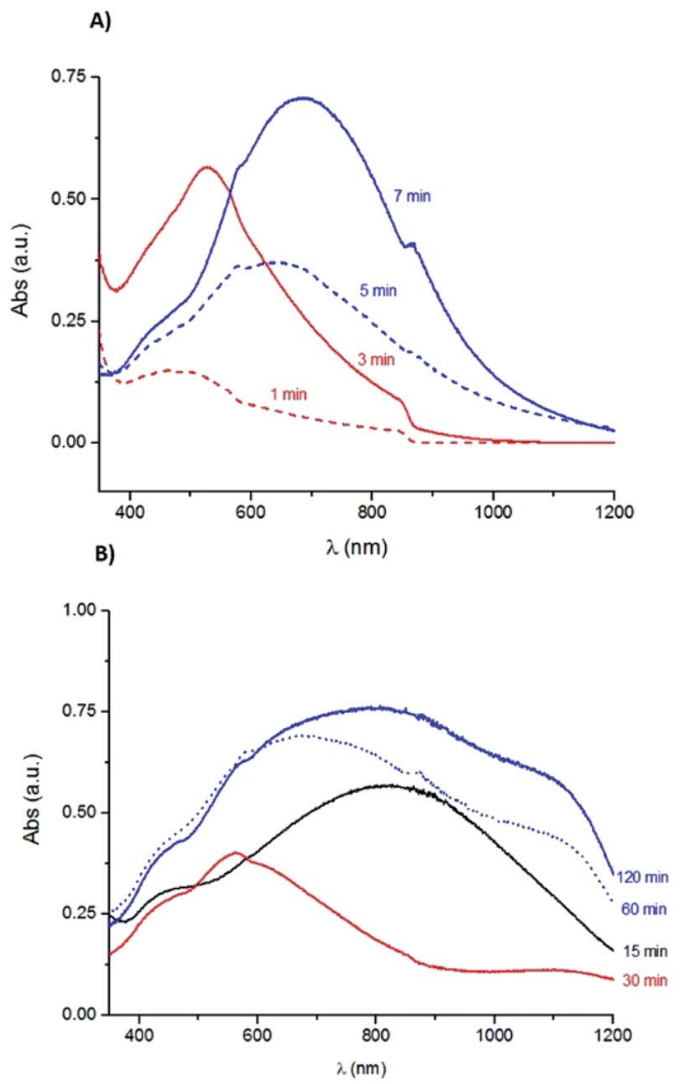

C)

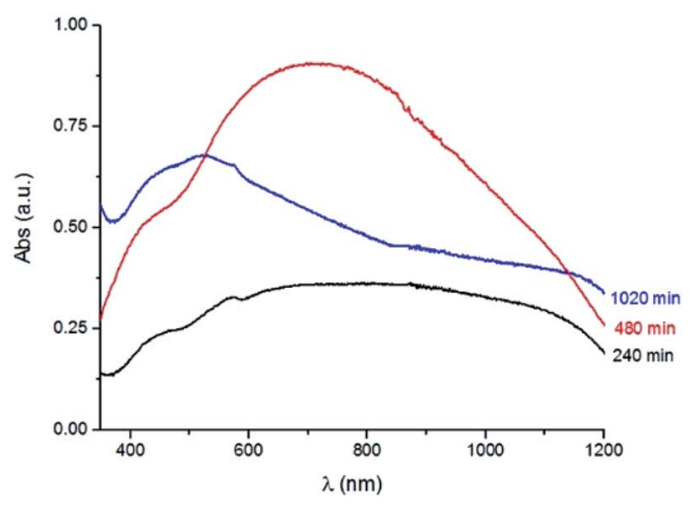

Fig. 2 UV-Vis absorption spectra obtained for the Ag samples corroded during (A) 1, 3, 5 and $7 \mathrm{~min}$; (B) 15, 30, 60 and $120 \mathrm{~min}$; (C) 240, 480 and $1020 \mathrm{~min}$ in a $0.1 \mathrm{M} \mathrm{Na}_{2} \mathrm{~S}$ aqueous solution.

SEM-EDS. Fig. 3A shows the bare Ag surface before accelerated ageing. The grid marks are visible on the surfaces of samples immersed until $120 \mathrm{~min}$. The surface of the samples immersed during 1, 3 and 5 minutes are characterised by the presence of small near-spherical particles (Fig. 3C). The 7 and 15 minutes corroded surfaces present a uniform layer, composed of spherical particles which sizes increase with time. The layer has localised hollows resulting from the sulphidation process. ${ }^{47}$ The corrosion layer of the sample immersed during $30 \mathrm{~min}$, Fig. 3F, that appears thicker contains particles with well-defined boundaries. From 240 min onwards, the shape of the formed structures resemble crystallites. Fig. $3 \mathrm{H}$ shows Ag protrusions 

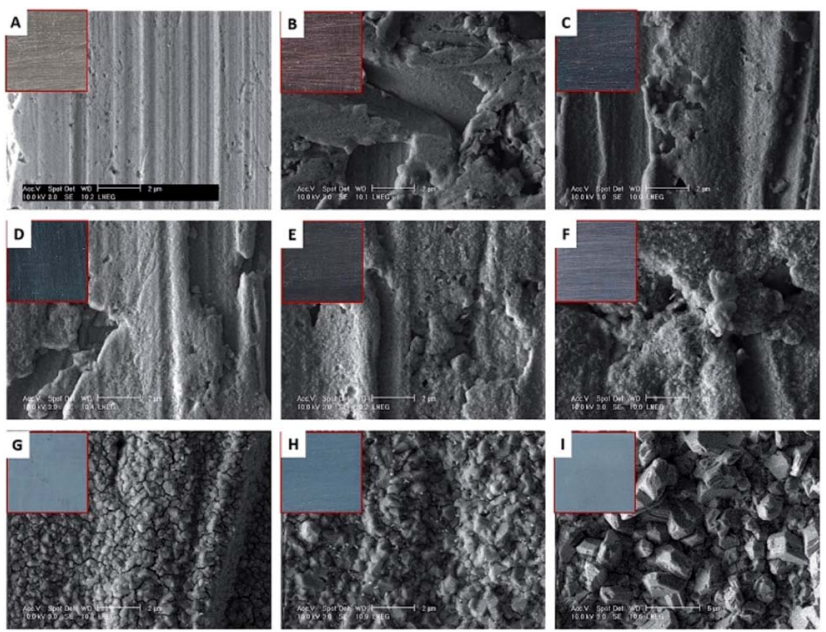

Fig. 3 SEM-secondary electron (SE) images of (A) Ag and corroded Ag by immersion in a $0.1 \mathrm{M} \mathrm{Na}_{2} \mathrm{~S}$ aqueous solution at: (B) $3 \mathrm{~min}$, (C) $5 \mathrm{~min}$, (D) $7 \mathrm{~min},(E) 15 \mathrm{~min},(\mathrm{~F}) 30 \mathrm{~min},(\mathrm{G}) 60 \mathrm{~min},(\mathrm{H}) 240 \mathrm{~min}$ and (I) $1020 \mathrm{~min}$ (scale bar is $2 \mu \mathrm{m}$ for (A to $\mathrm{H}$ ) and $5 \mu \mathrm{m}$ for $(\mathrm{I})$ ).

caused by the electron beam acceleration voltage as reported by Morales-Masis et al. $^{48}$

Table 1 summarises the EDS data obtained for the $\mathrm{Ag}$ corroded samples. With the immersion time increase, the Ag content decreases and the $\mathrm{S}$ and $\mathrm{O}$ values increase. The increase of $\mathrm{S}$ content is more pronounced than the increase of $\mathrm{O}$. Keast et al. $^{11}$ attribute the increase of $\mathrm{S}$ to an $\mathrm{Ag}_{2} \mathrm{~S}$ corrosion layer thickening. For samples immersed more than $120 \mathrm{~min}$, the $\mathrm{Ag} / \mathrm{S}$ ratio in at\% is consistent with the presence of $\mathrm{Ag}_{2} \mathrm{~S}$, based on the stoichiometry of this compound.

XRD analysis allowed to identify $\alpha-\mathrm{Ag}_{2} \mathrm{~S}$ for all the samples except for the sample immersed during $1 \mathrm{~min}$. As shown in Fig. 4, the intensity of the different $\mathrm{Ag}_{2} \mathrm{~S}$ diffraction peaks increases with the immersion time, which can be justified either by an increase of the compound quantity or by an increase of the degree of crystallisation of the corrosion products.

Table 1 Elemental composition by EDS (wt\%), normalised to $100 \%$, of Ag corroded samples

\begin{tabular}{|c|c|c|c|}
\hline \multirow[b]{3}{*}{ Sample ID } & \multicolumn{3}{|c|}{ Composition in wt $\%$} \\
\hline & \multirow{2}{*}{$\frac{\mathrm{Ag}}{\mathrm{L} \alpha}$} & \multirow{2}{*}{$\frac{\mathrm{S}}{\mathrm{K} \alpha}$} & \multirow{2}{*}{$\frac{\mathrm{O}}{\mathrm{K} \alpha}$} \\
\hline & & & \\
\hline $1 \mathrm{~min}$ & 97.7 & 1.5 & 0.8 \\
\hline $3 \mathrm{~min}$ & 97.7 & 1.2 & 1.2 \\
\hline $5 \mathrm{~min}$ & 97.6 & 1.5 & 0.6 \\
\hline $7 \mathrm{~min}$ & 97.3 & 1.5 & 0.9 \\
\hline $15 \mathrm{~min}$ & 97.8 & 1.5 & 0.7 \\
\hline $30 \mathrm{~min}$ & 96.7 & 3.0 & 0.3 \\
\hline $60 \mathrm{~min}$ & 91.2 & 7.2 & 1.6 \\
\hline $120 \mathrm{~min}$ & 88.2 & 10.7 & 1.2 \\
\hline $240 \mathrm{~min}$ & 88.3 & 10.4 & 1.3 \\
\hline $480 \mathrm{~min}$ & 87.2 & 11.5 & 1.3 \\
\hline $1020 \mathrm{~min}$ & 86.9 & 11.8 & 1.3 \\
\hline
\end{tabular}

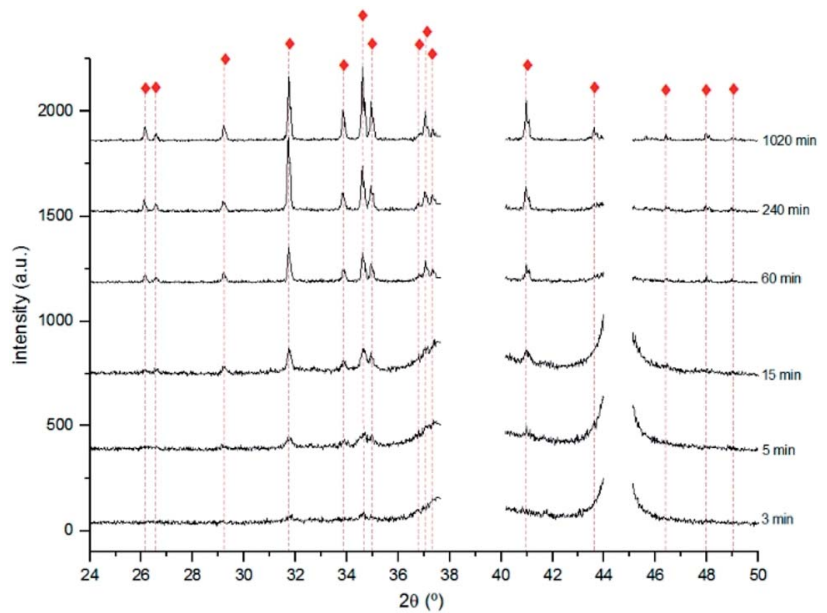

Fig. 4 X-ray diffractograms obtained for the 3, 5, 15, 60, 240 and 1020 min corroded pure $\mathrm{Ag}$ with the identification of the main diffraction peaks of $\mathrm{Ag}_{2} \mathrm{~S} \diamond$ (PCD file no. 00-014-0072).

For immersion time inferior to $240 \mathrm{~min}$, the most intense diffraction peaks are distinct from those reported for $\alpha-\mathrm{Ag}_{2} \mathrm{~S}$.

Fig. 5 shows the diffractogram obtained for the $240 \mathrm{~min}$ sample. The highest intensity peak corresponds to the (103) diffraction plane of $\mathrm{Ag}_{2} \mathrm{~S}$ instead of the expected (121). This difference can be justified by a distinct crystal orientation acquired during the growing process. ${ }^{48}$ The presence of $\mathrm{Ag}_{2} \mathrm{O}$ suggested by the UV-Vis spectra obtained for the 3 min sample was not confirmed by XRD. This can be justified either by its absence or presence at too low quantities, or by a noncrystalline structure. Data indicates the formation of $\mathrm{Ag}_{2} \mathrm{~S}$ only.

The Ag corrosion layer thicknesses were assessed by ex situ ellipsometry. For each sample, the ellipsometric parameters, azimuthal angle $(\Psi)$ and phase shift $(\Delta)$ were measured at $65^{\circ}$ and $70^{\circ}$ and the data fitted with a two-layer model in

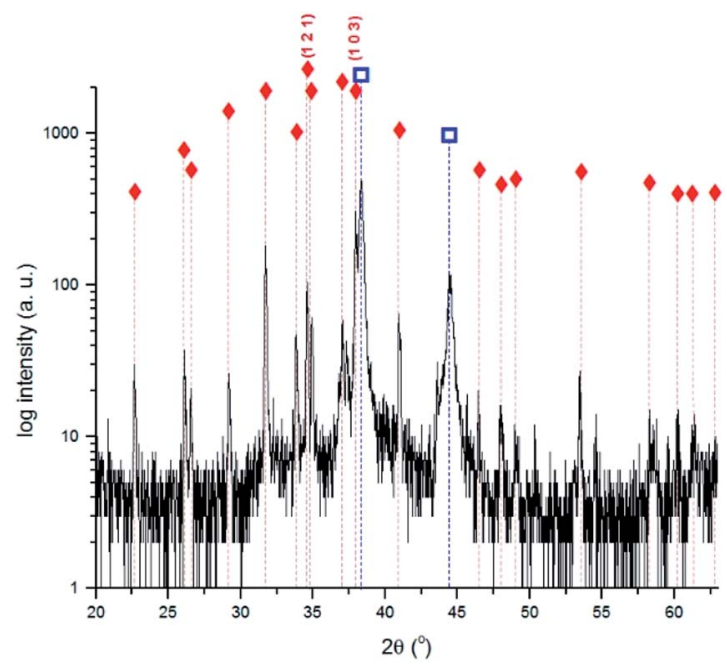

Fig. 5 X-ray diffractogram obtained for the 240 min corroded $\mathrm{Ag}$ sample with the identification of the main diffraction peaks of $\mathrm{Ag}$ and $\mathrm{Ag}_{2} \mathrm{~S}$. $\square \mathrm{Ag}$ (PCD file no. 00-004-0783); $\mathrm{Ag}_{2} \mathrm{~S}$ (PCD file no. 00-0140072). 
a multiangle approach. This model considers one homogeneous and isotropic layer on a semi-infinite homogeneous substrate, and allows the estimation of the thickness of the corrosion layer, being known the optical properties of the substrate. The obtained dielectric constants, refractive index $(n)$ and extinction coefficient $(k)$ are effective values (in the restrict sense of the optical outcome) and not necessarily characteristic of a single compound. Table 2 presents the complex refractive index and the computed thickness of the corrosion films for the samples immersed until $30 \mathrm{~min}$. The thickness values obtained are higher than those reported for $\mathrm{Ag}_{2} \mathrm{~S}$ layer formed in natural environments $^{49,50}$ and by artificial corrosion. ${ }^{34,51}$

The obtained data indicate that $\alpha-\mathrm{Ag}_{2} \mathrm{~S}$ is, as expected, the main corrosion product of pure $\mathrm{Ag}$ immersed in the sulphide solution. The formation of this compound occurs in a continuous process. At the early stages of corrosion, there is the nucleation of small particles of $\mathrm{Ag}_{2} \mathrm{~S}$ that increase in size with the immersion time until they join until a continuous film develops. ${ }^{39}$ With immersion time increases, the layer becomes uniform, containing crystalline $\mathrm{Ag}_{2} \mathrm{~S}$. Based on the composition and morphology of the corroded surface, it can be suggested that the surface colour variation is related to the size and shape of the $\mathrm{Ag}_{2} \mathrm{~S}$ particles and to the film thickness.

\subsection{Copper corroded surfaces characterisation}

Fig. 6 shows the colour variation of the $\mathrm{Cu}$ corroded surfaces with the immersion time. Alike the colour variation reported for pure $\mathrm{Cu}$ corroded in $\mathrm{Na}_{2} \mathrm{~S}$ solutions, ${ }^{27,42}$ the surface of samples change from violet $(1 \mathrm{~min})$ to blue-green ( $3 \mathrm{~min})$, green ( 5 and 7 $\mathrm{min}$ ), violet (15 $\mathrm{min}$ ), dark violet (30 $\mathrm{min}$ ), blue-grey (60 to 240 $\mathrm{min}$ ) and then grey-black (480 and $1020 \mathrm{~min}$ ). A violet tone is observed for samples immersed during 1 and 15 minutes whilst those immersed 3, 5 and 7 minutes have green tones.

The UV-Vis absorption spectrum shown in Fig. 7, obtained for the sample corroded during $1 \mathrm{~min}$, has a well-defined band. This band has a maximum absorbance at $560 \mathrm{~nm}$ corresponding to a $1.78 \mathrm{eV}$ band gap energy, which can be ascribed to the presence of $\mathrm{Cu}_{2} \mathrm{O} .{ }^{52}$ For the sample immersed during $3 \mathrm{~min}$, two bands are observed: one in the same wavelength range as in the previous sample, but with lower intensity, and a well-defined band with a maximum at $670 \mathrm{~nm}$. The latter band may correspond to an increase of the particles size.

For samples immersed during 5 and 7 minutes, the second band shifts towards higher wavelengths attaining a maximum

Table 2 Complex refractive index ( $\tilde{n})$ of the corrosion layer formed on Ag samples and their thicknesses $(d)$

\begin{tabular}{lll}
\hline Sample ID & $\tilde{n}$ & $d(\mathrm{~nm})$ \\
\hline $1 \mathrm{~min}$ & $3.0-0.1 \mathrm{i}$ & $118 \pm 0.6$ \\
$3 \mathrm{~min}$ & $3.0-0.1 \mathrm{i}$ & $126 \pm 1.3$ \\
$5 \mathrm{~min}$ & $3.0-0.4 \mathrm{i}$ & $127 \pm 2.6$ \\
$7 \mathrm{~min}$ & $3.0-0.4 \mathrm{i}$ & $129 \pm 0.5$ \\
$15 \mathrm{~min}$ & $3.0-0.4 \mathrm{i}$ & $214 \pm 0.5$ \\
$30 \mathrm{~min}$ & $3.0-0.3 \mathrm{i}$ & $222 \pm 0.4$
\end{tabular}
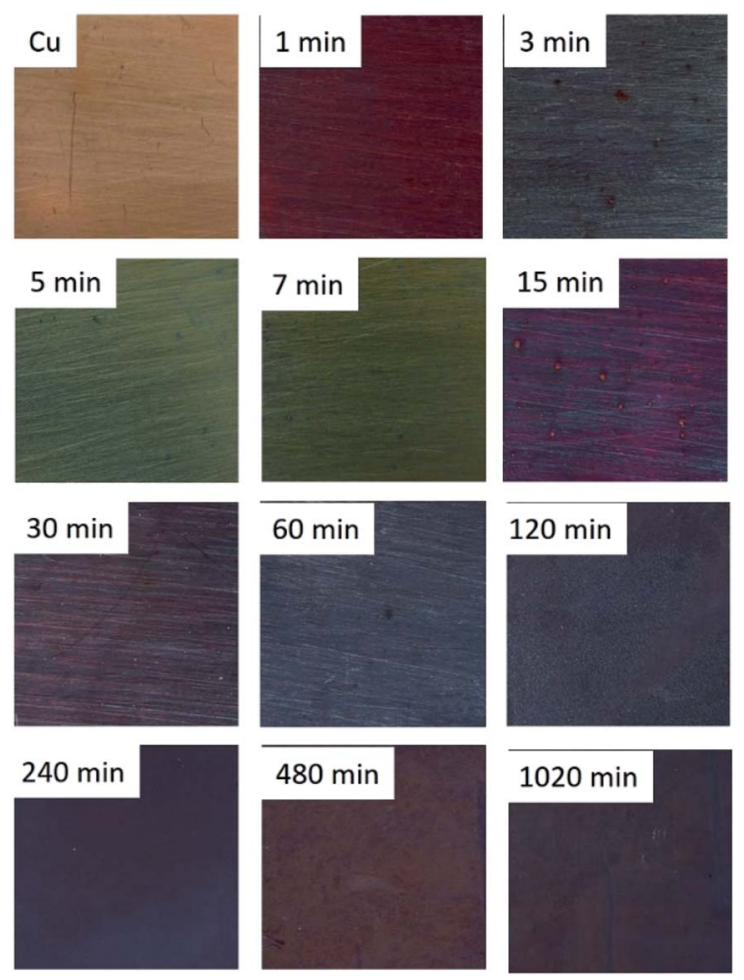

Fig. 6 Surface colour of the corroded Cu samples immersed during 1 , $3,5,7,15,30,60,120,240,480$ and $1020 \mathrm{~min}$ in a $0.1 \mathrm{M} \mathrm{Na}_{2} \mathrm{~S}$ aqueous solution.

of absorbance at $856 \mathrm{~nm}$ and $848 \mathrm{~nm}$, respectively. These bands correspond to $1.1 \mathrm{eV}$ and $1.2 \mathrm{eV}$ band gap energies, the latter value is reported for the formation of both $\mathrm{Cu}_{2} \mathrm{~S}^{53}$ and $\mathrm{Cu}_{2} \mathrm{O}$ particles. $^{54}$

This band shifts to lower wavelengths for the sample immersed during $15 \mathrm{~min}$. The maximum absorbance reached, around $560 \mathrm{~nm}$, is identical to the one observed in the spectrum of the sample immersed during $1 \mathrm{~min}$. This shift can be related to the nucleation of new particles of distinct size, similar to those formed on the $1 \mathrm{~min}$ sample surface. Since the optical properties also depend on the size and shape of the formed particles, ${ }^{53}$ this result supports the colour similarity cited above. For the samples immersed during 30 min onwards, the bands broadening should be related to the corrosion layer thickening.

SEM observation of the sample immersed during $3 \mathrm{~min}$ (Fig. 8B) revealed the presence of a uniform layer composed of small round particles. The layer morphology reminds the one reported for $\mathrm{Cu}_{2} \mathrm{~S}$ films. ${ }^{42}$ The corrosion layer thickens with the immersion time increase and, from an immersion time of $5 \mathrm{~min}$ onwards, it covers the grit marks (Fig. 8C).

Round particles of different sizes can be seen in the corrosion layer developed on the sample immersed 15 min (Fig. 8E). For longer immersion times, the particles change to an undefined shape that is characteristic of the layer growth mechanism. ${ }^{55-57}$ On samples immersed during times longer than $60 \mathrm{~min}$, the particles have either a round or a laminar shape (Fig. 8F-I). The latter can be ascribed to $\mathrm{Cu}_{2} \mathrm{~S}^{.56,57}$ 


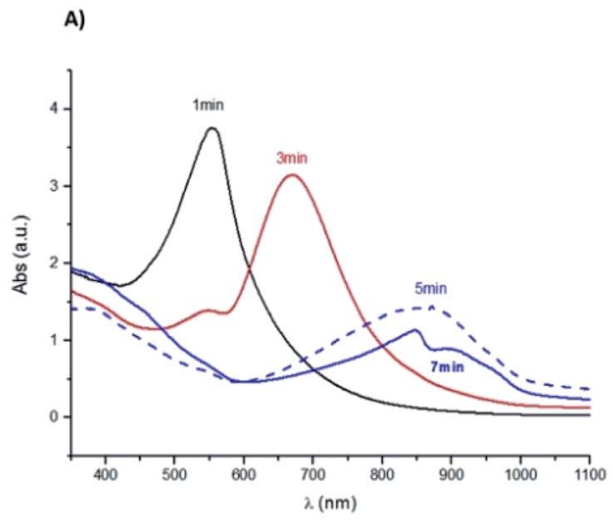

B)

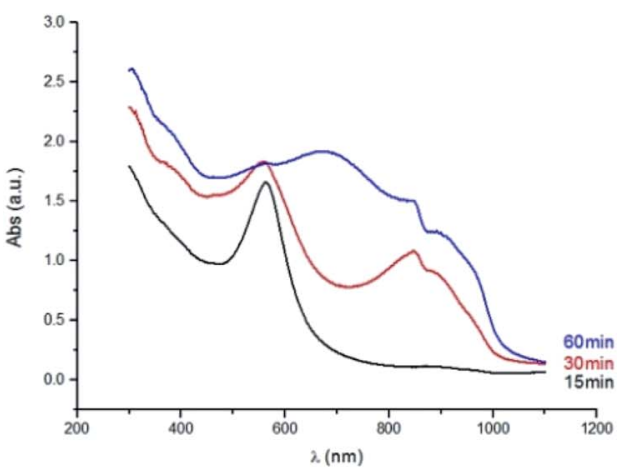

c)

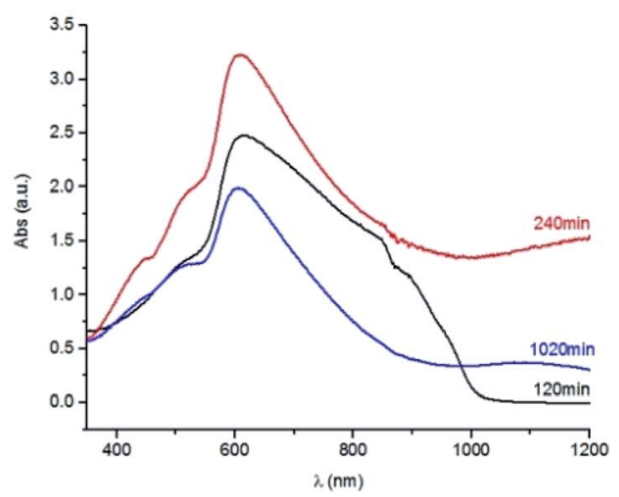

Fig. 7 UV-Vis absorption spectra for the Cu samples corroded during (A) 1, 3, 5 and 7 minutes; (B) 15, 30 and $60 \mathrm{~min}$; (C) 120, 240 and 1020 min.

Table 3 summarises the EDS data obtained for the corroded samples. With the immersion time increase, the $\mathrm{S}$ and $\mathrm{O}$ contents increase and the $\mathrm{Cu}$ content decreases. The accentuated increase of $\mathrm{S}$ on the $60 \mathrm{~min}$ sample surface can be related to the formation of corrosion products with sulphur. The increase of $\mathrm{O}$ is more pronounced in the case of samples immersed during 240 and 1020 min, suggesting the formation of copper oxide.

The presence of $\mathrm{Cu}_{2} \mathrm{~S}$ was identified by XRD for all the samples with immersion times longer than $15 \mathrm{~min}$.

As shown in Fig. 9, $\mathrm{Cu}_{2} \mathrm{O}$ was identified by $\mathrm{XRD}$ for the 120 , 240 and 1020 minutes samples suggesting the formation of two
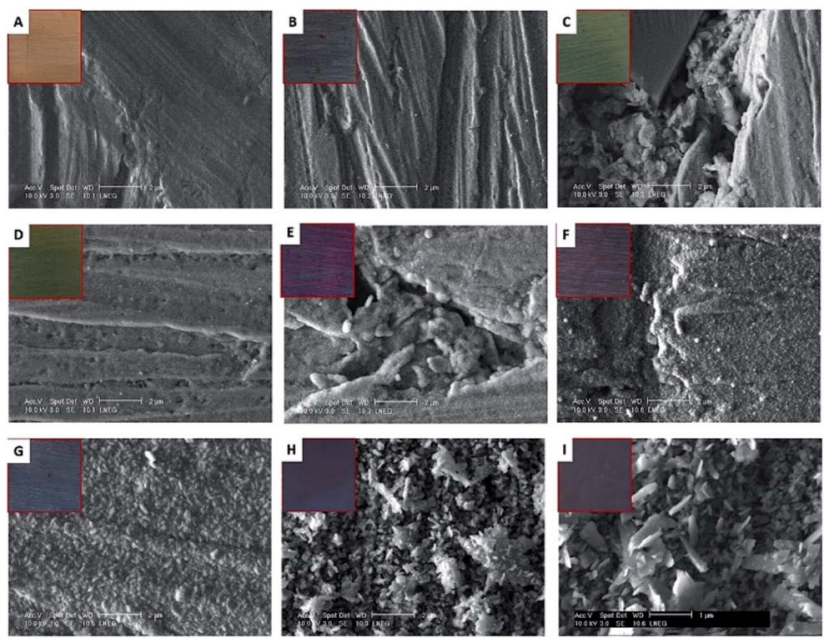

Fig. 8 SEM-SE images of (A) pure $\mathrm{Cu}$ and corroded $\mathrm{Cu}$ by immersion in a $0.1 \mathrm{M} \mathrm{Na}_{2} \mathrm{~S}$ aqueous solution at: (B) $3 \mathrm{~min}$, (C) $5 \mathrm{~min}$, (D) $7 \mathrm{~min},(\mathrm{E})$ $15 \mathrm{~min},(\mathrm{~F}) 30 \mathrm{~min},(\mathrm{G}) 60 \mathrm{~min},(\mathrm{H}) 240 \mathrm{~min}$ and (I) $1020 \mathrm{~min}$ (scale bar is $2 \mu \mathrm{m}$ for (A to $\mathrm{G})$ and $1 \mu \mathrm{m}$ for $(\mathrm{H}$ and $\mathrm{I})$ ).

Table 3 Elemental composition by EDS (wt\%), normalised to $100 \%$, of Cu corroded samples

\begin{tabular}{llrl}
\hline & \multicolumn{2}{l}{ Composition in wt\% } \\
\cline { 2 - 4 } & \multicolumn{2}{c}{$\mathrm{Cu}$} & $\mathrm{O}$ \\
\cline { 2 - 3 } & $\mathrm{K} \alpha$ & $\mathrm{S} \alpha$ & $\mathrm{K} \alpha$ \\
\hline Sample ID & 97.3 & 1.2 & 1.5 \\
$1 \mathrm{~min}$ & 96.7 & 1.5 & 1.8 \\
$3 \mathrm{~min}$ & 93.6 & 4.9 & 1.5 \\
$5 \mathrm{~min}$ & 94.5 & 3.5 & 2.1 \\
$7 \mathrm{~min}$ & 95.1 & 3.2 & 1.6 \\
$15 \mathrm{~min}$ & 92.1 & 5.5 & 2.4 \\
$30 \mathrm{~min}$ & 82.8 & 8.8 & 2.4 \\
$60 \mathrm{~min}$ & 88.4 & 4.6 & 3.6 \\
$120 \mathrm{~min}$ & 87.7 & 10.2 & 7.7 \\
$240 \mathrm{~min}$ & 86.3 & 7.1 & 3.4 \\
$480 \mathrm{~min}$ & 83.8 & & 9.1 \\
$1020 \mathrm{~min}$ & & & \\
\hline
\end{tabular}

different compounds for immersion times longer than $60 \mathrm{~min}$. The highest intensity peaks of $\mathrm{Cu}_{2} \mathrm{~S}$ are different from those reported in the PCD file no. 00-033-0490 showing that it grows with a distinct crystal orientation. The formation of $\mathrm{Cu}_{2} \mathrm{O}$ could result from the $\mathrm{Cu}_{2} \mathrm{~S}$ oxidation. With the corrosion layer thickening, cracks and defects appear allowing $\mathrm{S}$ to react with $\mathrm{Cu}$, to form $\mathrm{Cu}_{2} \mathrm{~S}$.

The corrosion layer thickness was also assessed for the $\mathrm{Cu}$ samples by $e x$ situ ellipsometry using a multiangle analysis $\left(70^{\circ}\right.$ and $60^{\circ}$ ) and the two-layer model. Table 4 presents the complex refractive index and the estimated corrosion film thickness for the samples corroded until $60 \mathrm{~min}$. The values obtained for the sample immersed during $1 \mathrm{~min}$ are in accordance with those reported for $\mathrm{Cu}_{2} \mathrm{~S}$ films with violet colour surfaces. ${ }^{42}$

Other information, such as the corrosion layer structural composition, can be retrieved from the dielectric constants. The composition was estimated by modelling the corrosion film 


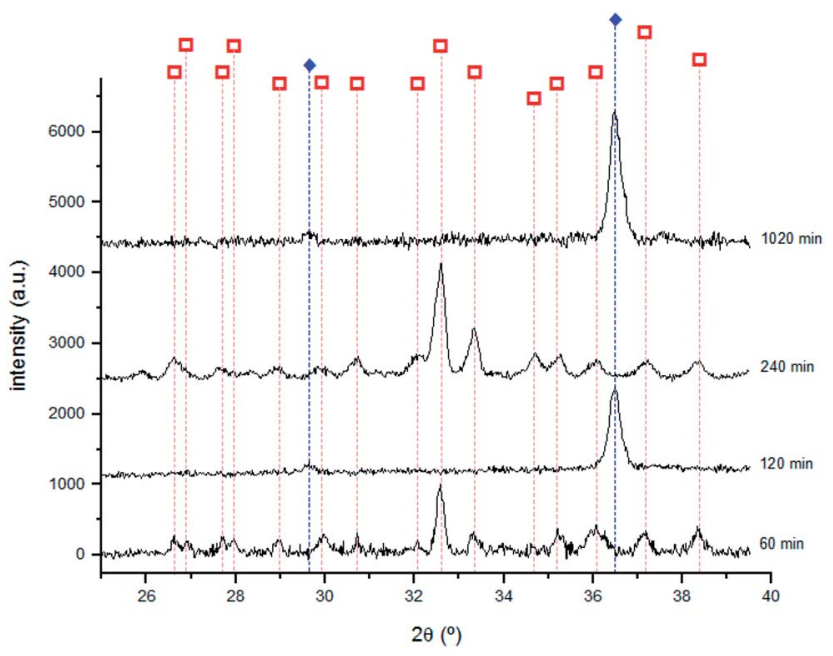

Fig. 9 X-ray diffractograms obtained for the samples immersed 60 , 120,240 and 1020 min with the identification of main diffraction peaks of $\mathrm{Cu}_{2} \mathrm{~S}$ and $\mathrm{Cu}_{2} \mathrm{O}$. $\mathrm{Cu}_{2} \mathrm{~S} \square$ (PCD file no. 00-033-0490); $\mathrm{Cu}_{2} \mathrm{O}$ (PCD file no. 00-077-0199).

Table 4 Complex refractive index ( $\tilde{n})$ of the corrosion layer formed on Cu samples and their thicknesses (d)

\begin{tabular}{lll}
\hline Sample ID & $\tilde{n}$ & $d(\mathrm{~nm})$ \\
\hline $1 \mathrm{~min}$ & $3.0-0.13 \mathrm{i}$ & $129 \pm 0.3$ \\
$3 \mathrm{~min}$ & $3.0-0.11 \mathrm{i}$ & $135 \pm 0.6$ \\
$5 \mathrm{~min}$ & $3.0-0.11 \mathrm{i}$ & $209 \pm 0.5$ \\
$7 \mathrm{~min}$ & $3.0-0.11 \mathrm{i}$ & $300 \pm 0.4$ \\
$15 \mathrm{~min}$ & $3.0-0.11 \mathrm{i}$ & $332 \pm 0.8$ \\
$30 \mathrm{~min}$ & $3.0-0.28 \mathrm{i}$ & $326 \pm 0.6$ \\
$60 \mathrm{~min}$ & $3.0-0.23 \mathrm{i}$ & $340 \pm 0.6$
\end{tabular}

structure using the Bruggeman Effective Medium Approximation (BEMA) theory. ${ }^{58}$ In this model, the corrosion layer structure is considered as a mixture of known compounds. ${ }^{59}$ Based on the elemental composition obtained by EDS (Table 3) that identified the presence of $\mathrm{S}$ and $\mathrm{O}$, the corrosion layer could be modelled as a combination of $\mathrm{Cu}_{2} \mathrm{~S}$ and $\mathrm{Cu}_{2} \mathrm{O}$, using reported $n$ and $k$ values. ${ }^{60,61}$ For samples corroded until $5 \mathrm{~min}$, a mixture of $\mathrm{Cu}_{2} \mathrm{O} / \mathrm{Cu}_{2} \mathrm{~S}$ with relative proportions of $85 \pm 5 / 15 \pm 5$ vol\% was found. For longer immersion times (until $60 \mathrm{~min}$ ), it prevails the $\mathrm{Cu}_{2} \mathrm{~S}$ component with a concentration ranging from 70 to 80 vol\%. The latter result is in agreement with the XRD data.

The 15 min sample could not be fitted by the BEMA model. The similar violet surface colour and UV-Vis spectra obtained for the samples corroded during 1 and 15 minutes (Fig. 6 and 7) suggested the presence of similar species at the surface. However, the estimated corrosion layer for the 15 min sample is, as expected, higher than the thickness of the 1 min corrosion layer. For this reason, the existence of a multilayered corrosion film was considered, and data was fitted using the three-layer model. The results of this theoretical model indicate the presence of a $160 \mathrm{~nm}$ inner-layer composed of $80 \mathrm{vol} \%$ of $\mathrm{Cu}_{2} \mathrm{O}$ and $20 \mathrm{vol} \% \mathrm{Cu}_{2} \mathrm{~S}$ and a $230 \mathrm{~nm}$ outer layer composed exclusively of
$\mathrm{Cu}_{2} \mathrm{O}$. These values are in agreement with the calculated corrosion layer thickness (332 $\mathrm{nm}$ by the multiangle ellipsometry approach) and with the UV-Vis data.

The results obtained for the corrosion of $\mathrm{Cu}$ in sulphide solution indicate that the process follows the reported copper sulphidation mechanisms. ${ }^{37-40}$ At early corrosion stages, occurs the formation of $\mathrm{Cu}_{2} \mathrm{O}$ followed by the formation of $\mathrm{Cu}_{2} \mathrm{~S}$. In fact, the surface characterisation of the samples immersed until 15 minutes indicates the coexistence of $\mathrm{Cu}_{2} \mathrm{O}$ and $\mathrm{Cu}_{2} \mathrm{~S}$. For immersion times between 15 and 60 minutes, it was shown the prevalence of $\mathrm{Cu}_{2} \mathrm{~S}$, with a layer thickening with the immersion time. For longer immersion times, the $\mathrm{Cu}_{2} \mathrm{~S}$ is interspersed with the formation of $\mathrm{Cu}_{2} \mathrm{O}$, possibly due to the oxidation of the $\mathrm{Cu}_{2} \mathrm{~S}$ layer. Like in the case of $\mathrm{Ag}$, the different colours of the corroded surface are a result of the size and shape of the corrosion products particles and of the corrosion layer thickness.

\subsection{Ag and $\mathrm{Cu}$ corrosion versus sterling silver corrosion}

When the colour of corroded pure $\mathrm{Ag}$ is compared with the colour of corroded sterling silver, it can be seen that at the early stages of corrosion the colour variation of pure $\mathrm{Cu}$ and sterling silver are in appearance alike. For longer immersion times the colour variation of sterling silver approaches that of pure Ag. The corrosion films of pure $\mathrm{Ag}$ and $\mathrm{Cu}$ mainly contain $\mathrm{Ag}_{2} \mathrm{~S}$ and $\mathrm{Cu}_{2} \mathrm{~S}$ respectively, suggesting that the surface colour variation depends on the corrosion film thickness. The colour variation of sterling silver is instead due not only to the film thickness but also to the formation of different compounds. At the early stages of corrosion, based on the corroded surface composition and on the surface colour variation, we can suggest a significant influence of the $\mathrm{Cu}$ on the corrosion mechanism of sterling silver. The formation of $\mathrm{Cu}$ compounds on the surface of sterling silver for early stages of corrosion was suggested by Tissot et $a .^{10}$ Nevertheless, these new data on the pure elements provide evidence on the predominant role of $\mathrm{Cu}$ even when this element is present at low concentrations $(7.5 \mathrm{wt} \% \mathrm{Cu}$ in the sterling silver).

The morphology of the corroded surfaces of the pure elements and the alloy were compared. In the case of Ag, it was shown the nucleation and growth of the same species, but with sizes and shapes that change with the immersion time. $\mathrm{Cu}$ presents identical morphologies until $60 \mathrm{~min}$ of immersion time, but for longer times the formation of particles with laminar and round shapes was observed. At the early stages of corrosion, the surface morphology of the corroded sterling silver has similarities with those of $\mathrm{Ag}$ and $\mathrm{Cu}$. For longer corrosion times, the morphology of the sterling silver corrosion evidently approaches the morphology of the Ag corrosion. The corrosion layer was found to be thicker for pure elements. When all the samples immersed during $1 \mathrm{~min}$ are compared, the estimated corrosion layer thickness is about $90 \mathrm{~nm}$ higher for the pure elements than for sterling silver.

$\mathrm{Ag}$ is the main constituent element of the sterling silver alloy. It would be expected a major influence of this element on the corrosion mechanisms of the alloy. Nonetheless, data (colour, composition and morphology) suggest that the corrosion 

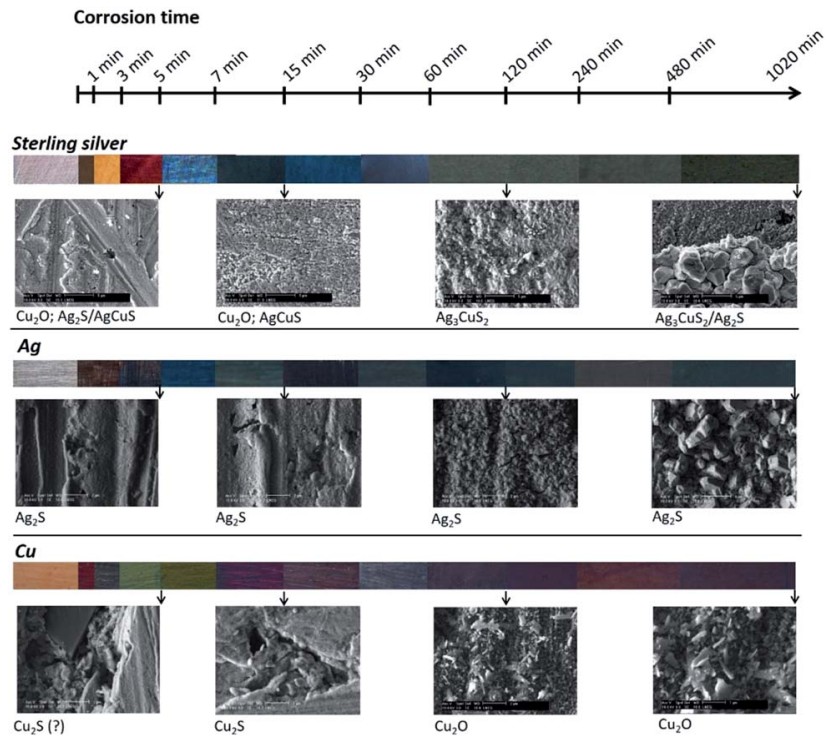

Fig. 10 Schema of sterling silver, ${ }^{10}$ copper and silver surface colour, morphology and composition variation with the corrosion time increase in a $0.1 \mathrm{M} \mathrm{Na}_{2} \mathrm{~S}$ aqueous solution.

mechanism of sterling silver is predominantly influenced by $\mathrm{Cu}$ at the early stages of corrosion, and by $\mathrm{Ag}$ for longer times. However, it should be highlighted that sterling silver develops a layer-by-layer corrosion structure. This type of structure was not observed for any of the pure metals, suggesting a distinct corrosion mechanism. Fig. 10 summarises this discussion.

\section{Conclusions}

In this work, sheets of pure $\mathrm{Ag}$ and pure $\mathrm{Cu}$ used by jewellers to fabricate sterling silver were corroded by immersion in an aqueous $\mathrm{Na}_{2} \mathrm{~S}$ solution. The corroded surfaces were characterised with different analytical techniques. The results obtained for these pure metals were compared to data previously published for sterling silver, and their contribution to the alloy corrosion mechanism was analysed and discussed.

$\alpha-\mathrm{Ag}_{2} \mathrm{~S}$ is the main corrosion product of $\mathrm{Ag}$. For early corrosion stages, UV-Vis spectrophotometry and SEM indicated the formation of $\mathrm{Ag}_{2} \mathrm{~S}$ particles of different shapes and sizes, which increase in number and size with the immersion time. For longer immersion times, the corrosion layer becomes uniform and composed of crystalline $\mathrm{Ag}_{2} \mathrm{~S}$, identified by XRD. The corrosion layer thickness was estimated to about $222 \mathrm{~nm}$ for samples immersed until $30 \mathrm{~min}$.

The characterisation by UV-Vis, ellipsometry and XRD of $\mathrm{Cu}$ corroded surfaces showed for early corrosion stages the coexistence of $\mathrm{Cu}_{2} \mathrm{O}$ and $\mathrm{Cu}_{2} \mathrm{~S}$. For longer immersion times, it was revealed the prevalence of $\mathrm{Cu}_{2} \mathrm{~S}$, and the surface morphology observed by SEM showed a layer thickening with time. For longer immersion times, $\mathrm{Cu}_{2} \mathrm{~S}$ and $\mathrm{Cu}_{2} \mathrm{O}$ were identified by $\mathrm{XRD}$, suggesting the $\mathrm{Cu}_{2} \mathrm{~S}$ oxidation. The corrosion layer thickness was estimated to about $340 \mathrm{~nm}$ for samples immersed until $60 \mathrm{~min}$.
The different colours of the $\mathrm{Ag}$ and $\mathrm{Cu}$ corroded surfaces are a result of the distinct size and shape of the corrosion products particles and of the corrosion layer thickness.

Based on the corroded surface composition it is possible to propose that the corrosion mechanisms of $\mathrm{Ag}$ and $\mathrm{Cu}$ are different from the corrosion mechanism of sterling silver. At the early stages of corrosion, the influence of $\mathrm{Cu}$ predominates whilst for longer corrosion times it is Ag that assumes the major role. In addition, at the early corrosion stages the colours of corroded sterling silver and corroded pure $\mathrm{Cu}$ are similar, while for longer corrosion times sterling silver acquires a colour close to that of pure Ag. The layer-by-layer structure observed for sterling silver was not observed for the pure metals, and therefore should be characteristic of this alloy corrosion mechanism.

\section{Acknowledgements}

This research was partially supported by the Fundação para a Ciência e Tecnologia (SFRH/BDE/51439/2011 and ID/MULTI/ 00612/2013).

\section{References}

1 T. Palomar, B. R. Barat, E. García and E. Cano, J. Cult. Herit., 2016, 17, 20.

2 A. Marquardt, E. M. Breitung, T. Drayman-Weisser, G. Gates and R. J. Phaneuf, Heritage Sci., 2015, 3, 37.

3 J. C. D. de Figueiredo Junior, S. S. Asevedo and J. H. R. Barbosa, Appl. Surf. Sci., 2014, 317, 67.

4 J. Novakovic, P. Vassiliou and E. Georgiza, Int. J. Electrochem. Sci., 2013, 8, 7223.

5 C. Liang, C. Yang and N. Huang, Surf. Coat. Technol., 2009, 203, 1034.

6 H. Kim and J. H. Payer, Corros. Sci. Technol., 2006, 5, 206.

7 M. Bernard, E. Dauvergne, M. Evesque, M. Keddam and H. Takenouti, Corros. Sci., 2005, 47, 663.

8 M. Evesque, M. Keddam and H. Takenouti, Electrochim. Acta, 2004, 49, 2937.

9 K. Hallet, D. Thickett, D. S. McPhail and R. J. Chater, Appl. Surf. Sci., 2003, 203-204, 789.

10 I. Tissot, O. C. Monteiro, M. A. Barreiros, V. Corregidor, J. Correia and M. F. Guerra, RSC Adv., 2016, 6, 51856.

11 V. J. Keast, T. A. Myles, N. Shahcheraghi and M. B. Cortie, J. Nanopart. Res., 2016, 18, 45.

12 J. Hirunyagird, G. Lothongkum and E. Nisaratanaporn, Adv. Mater. Res., 2014, 894, 138.

13 C. Kleber, R. Wiesinger, J. Schnöller, U. Hilfrich, H. Hutter and M. Schreiner, Corros. Sci., 2008, 50, 1112.

14 A. M. Hacke, C. Carr, A. Brown and D. Howell, J. Mater. Sci., 2003, 38, 3307.

15 P. Storme, O. Schalm and R. Wiesinger, Heritage Sci., 2015, 3, 25.

16 A. Cusma, M. Sebastiani, D. De Felicis, A. Basso and E. Bemporad, Coatings, 2015, 5, 78.

17 C. Leygraf, I. O. Wallinder, J. Tidblad and T. Graedel, in The Atmospheric Corrosion, ed. C. Leygraf, I. O. Wallinder, J. 
Tidblad and T. Graedel, John Wiley \& Sons, Inc., Hoboken, NJ, USA, 2016, pp. 337-347.

18 C. E. Sanders, D. Verreault, G. S. Frankel and H. C. Allen, J. Electrochem. Soc., 2015, 162, C630.

19 R. Wiesinger, R. Grayburn, M. Dowsett, P.-J. Sabbe, P. Thompson, A. Adriaens and M. Schreiner, J. Anal. At. Spectrom., 2015, 30, 694.

20 P. Homem, PhD thesis, Faculdade de Letras, Universidade do Porto, 2013.

21 T. W. H. Oates, M. Losurdo, S. Noda and K. Hinrichs, J. Phys. D: Appl. Phys., 2013, 46, 145308.

22 I. Martina, R. Wiesinger and M. Schreiner, J. Raman Spectrosc., 2013, 44, 770.

23 R. Wiesinger, I. Martina, C. Kleber and M. Schreiner, Corros. Sci., 2013, 77, 69.

24 I. Martina, R. Wiesinger, D. Jembrih-Simbürger and M. Schreiner, e-Preserv. Sci., 2012, 9, 1.

25 N. Li, PhD thesis, Université Pierre et Marie Curie-Paris VI, 2012.

26 C. E. Lemon, PhD thesis, Ohio State University, 2012.

27 S. Nakayama and T. Umemoto, SEI Tech. Rev., 2012, 74, 8.

28 C. Kebler, U. Hilfrich and M. Schreiner, Appl. Surf. Sci., 2007, 253, 3712.

29 J. L. Elechiguerra, L. Larios-Lopez, C. Liu, D. GarciaGutierrez, A. Camacho-Bragado and M. J. Yacaman, Chem. Mater., 2005, 17, 6042.

30 H. Kim, Mater. Corros., 2003, 54, 243.

31 D. W. Rice, P. Peterson, E. B. Rigby, P. B. P. Phipps, R. J. Cappell and R. Tremoureux, J. Electrochem. Soc., 1981, 128, 275.

32 V. I. Birss and G. A. Wright, Electrochim. Acta, 1981, 12, 1809.

33 T. Baše, Z. Bastl, V. Havránek, K. Lang, J. Bould, M. G. S. Londesborough, J. Macháček and J. Plešek, Surf. Coat. Technol., 2010, 204, 2639.

34 Y. B. Amor, E. Sutter, H. Takenouti, B. Tribollet, M. Boinet, R. Faure, J. Balencie and G. Durieu, Electrochim. Acta, 2014, 131, 89.

35 I. Carbone, Q. Zhou, B. Vollbrecht, L. Yang, S. Medling, A. Bezryadina, F. Bridges, G. B. Alers, J. T. Norman and T. Kinmen, J. Vac. Sci. Technol., A, 2011, 29, 051505.

36 N. Taniguchi and M. Kawasaki, J. Nucl. Mater., 2008, 379, 154.

37 M. Reid, J. Punch, C. Ryan, L. F. Garfias, S. Belochapkine, J. P. Franey, G. E. Derkits Jr and W. D. Reents Jr, J. Electrochem. Soc., 2007, 154, C209.

38 J. C. Barbour, J. W. Braithwaite and A. F. Wright, Nucl. Instrum. Methods Phys. Res., Sect. B, 2001, 175, 382.
39 T. E. Graedel, J. P. Franey, G. J. Gualtieri, G. W. Kammlott and D. L. Malm, Corros. Sci., 1985, 25, 1163.

40 S. P. Sharma, J. Electrochem. Soc., 1980, 127, 21.

41 K. P. FitzGerald, J. Nairn, G. Skennerton and A. Atrens, Corros. Sci., 2006, 48, 2480.

42 I. Grozdanov and M. Najdoski, J. Solid State Chem., 1995, 114, 469.

43 M. Valodkar, S. Modi, A. Pal and S. Thakore, Mater. Res. Bull., 2011, 46, 384.

44 R. Chen, N. T. Nuhfer, L. Moussa, H. R. Morris and P. M. Whitmore, Nanotechnology, 2008, 19, 1.

45 X. Wang, S. Li, H. Yu, J. Yu and S. Liu, Chem.-Eur. J., 2011, 17, 7777.

46 S. Kashida, N. Watanabe, T. Hasegawa, H. Iida, M. Mori and S. Savrasov, Solid State Ionics, 2003, 158, 167.

47 P. Chattopadhyay and S. Guha Roy, Indian J. Pure Appl. Phys., 2013, 51, 98.

48 M. Morales-Masis, S. J. van der Molen, W. T. Fu, M. B. Hesselberth and J. M. van Ruitenbeek, Nanotechnology, 2009, 20, 095710.

49 H. Gil, C. P. Buitrago and A. Echavarría, J. Solid State Electrochem., 2015, 19, 1817.

50 H. Águas, R. J. C. Silva, M. Viegas, L. Pereira, E. Fortunato and R. Martins, Phys. Status Solidi C, 2008, 5, 1215.

51 T. Tamai, IEEE Trans. Compon., Hybrids, Manuf. Technol., 1989, 12, 43.

52 Z. Wu, M. Shao, W. Zhang and Y. Ni, J. Cryst. Growth, 2003, 260, 490.

53 K. Itoh, T. Kuzuya and K. Sumiyama, Mater. Trans., 2006, 47, 1953.

54 M. R. Johan, M. S. M. Suan, N. L. Hawari and H. A. Ching, Int. J. Electrochem. Sci., 2011, 6, 6094.

55 M. Ramya and S. Ganesan, Iran. J. Sci. Technol., 2013, 37, 293.

56 T. Martino, R. Partovi-Nia, J. Chen, Z. Qin and D. W. Shoesmith, Electrochim. Acta, 2014, 127, 439.

57 J. Chen, Z. Qin and D. W. Shoesmith, Mater. Res. Soc. Symp. Proc., 2012, 1475, 465.

58 S. Berthier, Optique des milieux composites, Polytechnica, Paris, 1993.

59 A. Szekeres, S. Bakalova, S. Grigorescu, A. Cziraki, G. Socol, C. Ristoscu and I. N. Mihailescu, Appl. Surf. Sci., 2009, 255, 5271.

60 N. K. Abbas and N. J. Ghdeeb, Iraqi Journal of Physics, 2015, 13, 121.

61 Handbook of Optical Constants of Solids, ed. E. D. Palik, Academic Press, Boston, vol. 2, 1991. 